\title{
Lens protein glycation in diabetic and senile cataract patients
}

\author{
Prachi Shukla ${ }^{1}$, Manisha Arora ${ }^{2 *}$, Roshan Kumar Mahat ${ }^{3}$, Sudeep Kumar ${ }^{4}$, Sumesh Prasad Sah \\ 1,3,4 Assistant Professor, ${ }^{2}$ Professor and Head, ${ }^{5}$ Demonstrator, ${ }^{1}$ Dept. of Ophthalmology, ${ }^{2-5}$ Dept. of Biochemistry, Muzaffarnagar Medical \\ College, Muzaffarnagar, Uttar Pradesh, India
}

\section{Article Info}

Received: $4^{\text {th }}$ February, 2019

Accepted: $18^{\text {th }}$ May, 2019

Published Online: $9^{\text {th }}$ September, 2019

Keywords: Cataract, Crystallins, Diabetes mellitus, Glycation.

\begin{abstract}
Introduction: Cataract is an abnormality in lens, characterized by decreased transparency and increased cloudiness and may progress to severe visual impairment if left untreated. Glycation of lens protein crystallins is considered as the major mechanism for the formation of cataract. The study was undertaken with the aim to estimate glycated protein in lens of diabetic cataract patients and to compare it with senile cataracts.

Materials and Methods: A total of 60 lenses were collected. Of which, 30 were from diabetic cataract subjects and rest 30 were from subjects of senile cataract. Glycated protein was measured in the lenses of all participants.

Results: The level of lens glycated protein was found to be significantly increased in subjects of type 2 diabetes mellitus compared to senile cataract patients.

Conclusion: In conclusion, the results of the present study indicate that glycation of lens protein may play an important role in the development of cataract with greater extent in diabetic patients compared to senile group.
\end{abstract}

\section{Introduction}

Lens is considered to be the most important structures in the eyes and its main function is to refract the light to focus it on the retina that is located behind pupil and iris. ${ }^{1}$ Cataract is an abnormality in lens, characterized by decreased transparency and increased cloudiness. ${ }^{2}$ If left untreated, cataract can eventually progress to severe visual impairment or even blindness. Individuals with cataract are more likely to have substantially reduced vision-related quality of life and have increased risk of co-morbidity and mortality as compared to the general population. ${ }^{3}$ Cataract is considered as the major cause of visual impairment and blindness across the globe, especially in developing countries though it can be treated easily, safely, and cost efficiently. ${ }^{4}$ The main proteins present in the lens and the lens surfaces are crystallins, which are responsible for their refractive function. Any modification, aggregation and precipitation of crystallins cause the development of cataract. ${ }^{2}$ In the year 2010, it has been estimated that 94 million people were visually impaired and 20 million were blind because of cataract, accounting for one third $(33 \%)$ of all individuals with visual impairment and more than half $(51 \%)$ of blind cases worldwide. ${ }^{5}$ In India, it has been reported that 20 lakhs new cases of cataract is being added to the burden every year. ${ }^{6}$

The most common type of cataract is senile cataract, which occurs as consequences of the aging process and characterized by an initial opacity in the lens with subsequent swelling of the lens and final shrinkage with complete loss of transparency. ${ }^{7}$ The term senile refers to the fact that this type of cataract does not precede or involve specific ophthalmic or metabolic diseases. ${ }^{8,9}$ On the other hand, diabetes is considered as a major risk factor for producing opacification of lens and ultimately loss of vision. The process of development of cataract begins about 20 years before in diabetic people as compared with senile subjects. ${ }^{10}$ Formation of advanced glycation end products result from increased non enzymatic glycation of lens proteins and has been reported in both diabetes and in normal aging process but increased levels have been reported in individuals with type 2 diabetes mellitus ${ }^{12}$. The lens protein undergoes non-enzymatic glycation by reducing sugars. As a result, the conformation of lens is changes, leading to the formation of protein aggregates, which precipitate in the lens and causes lens opacity. ${ }^{10}$ The present study determines the levels of glycated protein in lens of diabetic cataract patients and to compare it with senile cataracts.

\section{Materials and Methods}

The present study was carried out in Ophthalmology and Biochemistry Departments of Muzaffarnagar Medical College, Muzaffarnagar, (U.P.), India. Ethical approval was taken from Institutional Ethical Committee prior to the study. Nuclear portion of lens were obtained from 60 individuals of either sex who underwent for routine extra-

*Corresponding Author: Manisha Arora, Professor and Head, Dept. of Biochemistry, Muzaffarnagar Medical College, Muzaffarnagar, India

Email: drmanishaarora@gmail.com

http://doi.org/10.18231/j.ijceo.2019.095 
capsular lens extraction at the Department of Ophthalmology. The age of study participants ranges between 45-75 years. A total of 60 lenses were obtained. Out of these, 30 were from subjects with diabetic cataracts and 30 were from senile cataract patients with no history of diabetes mellitus, having normal fasting plasma glucose.

From both diabetic and senile cataracts, nuclei were collected separately and recorded their weight and colour. After that, they were homogenized as described earlier. ${ }^{13}$ The lens homogenates obtained were then centrifuged at $10,000 \times \mathrm{g}$ for 20 minutes at $4^{0} \mathrm{C}$ and clear supernatant was used for estimation of glycated protein. Lens total protein and glycated protein were measured by the method of Lowry ${ }^{14}$ and phenol sulfuric acid method ${ }^{15}$ respectively.

About $4 \mathrm{ml}$ of blood was collected from all study participants under all aseptic precautions and dispensed into 2 different vials based on analysis to be done. About $2 \mathrm{ml}$ blood sample was taken in fluoride vial for estimation of fasting plasma glucose (FPG) and $2 \mathrm{ml}$ in EDTA vial for estimation of glycated hemoglobin in whole blood. Fasting plasma glucose was estimated by GOD-POD method on CPC Turbochem-100, a fully automated chemistry analyzer. HbAlc was estimated in whole EDTA blood by turbidimetric immunoassay method, using a commercially available kit from APTEC Diagnostics.

\section{Statistical Analysis}

Statistical package for Social Science version 20 (IBM, SPSS Statistics 20, Armonk, NY, USA) was used for statistical analysis of collected data. Mean and standard deviation (SD) of all the data were calculated and presented as mean \pm SD. Comparison of mean values of different parameters between diabetic and senile cataracts was tested using student unpaired ' $t$ ' test. Statistical significance was defined at $p<0.05$.

\section{Results}

Table 1 shows biochemical characteristics of the studied subjects. There were no significant differences in age and sex distribution between diabetic and senile cataract subjects, indicating that both the groups (i.e. diabetic and senile cataract patients) were age and gender matched. The levels of fasting plasma glucose and glycated hemoglobin in diabetic cataract patients were significantly increased as compared to non-diabetic senile cataracts. In addition, diabetic cataract patients had significantly increased lens glycated protein as compared to senile cataract patients. Fig. 1 shows the comparison of lens glycated protein between diabetic and senile cataracts.

Table 1: Biochemical characteristics of the studied subjects

\begin{tabular}{|c|c|c|}
\hline Variables & $\begin{array}{c}\text { Senile cataract } \\
\text { subjects }(\mathbf{n}=30)\end{array}$ & $\begin{array}{c}\text { Diabetic cataract } \\
\text { subjects }(\mathbf{n}=\mathbf{3 0})\end{array}$ \\
\hline Age (years) & $59.57 \pm 8.67$ & $58.57 \pm 9.05^{\mathrm{NS}}$ \\
\hline Sex (M/F) & $18 / 12$ & $16 / 14^{\mathrm{NS}}$ \\
\hline FPG (mg/dl) & $100.20 \pm 6.03$ & $163.73 \pm 10.95^{* *}$ \\
\hline HbA1c $(\%)$ & $5.01 \pm 0.75$ & $8.12 \pm 0.77^{* *}$ \\
\hline Lens glycated & $3.81 \pm 0.55$ & $5.96 \pm 0.72^{* *}$ \\
\hline
\end{tabular}

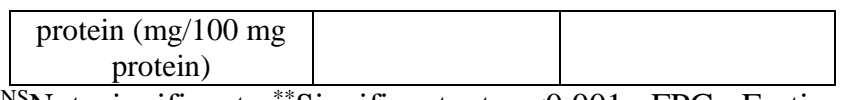

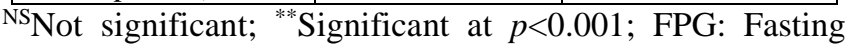
plasma glucose; HbA1c: Glycated hemoglobin

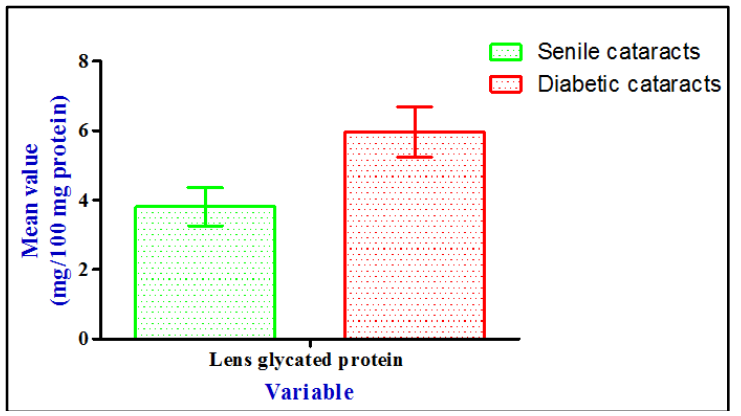

Fig. 1: Comparison of lens glycated protein between senile and diabetic cataracts

\section{Discussion}

Lens contains various structural proteins $(\alpha-, \beta-$, and $\gamma$ crystallin's), which are long lived and undergo a variety of post translational modifications, which includes glycation, carbonylation, steroid adduct formation, methionine oxidation, racemization, degredation and deamidation. As a result of these modifications, there occurs increased crosslinking of lens crystallins, which further aggregates and produce a high molecular weight material, responsible for opacification and hence cataract development. ${ }^{11,16}$

It has been suggested that glycation may also play important role in lens coloration. In the present study, we observed increase in the colour of lens from pale yellow to dark yellow in patients of senile cataract and from brown to dark brown in patients of diabetic cataract. This change in colour of lens may reflect a higher level of fluorescence of proteins caused by glycation in lens of senile and diabetic cataract patients. Long lived proteins viz. collagen and lens are highly susceptible to post translational modifications such as glycation, leading to cross-linking, aggregation and insolubilization of such proteins that could further lead to opacification and hence cataract. ${ }^{9,11}$

The transport of glucose in the lens is not dependent on insulin and hence in type 2 diabetes mellitus, there occurs increased concentration of glucose within the lens, which causes increased glycosylation of lens proteins. ${ }^{17}$ As compared to senile cataract patients, the diabetic cataract patients had significantly increased glycation of nuclear portion of lens, which is consonance with the finding of Duhaiman. ${ }^{9}$ The finding of our study indicates that hyperglycemia may induce non-enzymatic glycosylation of lens protein crystalline in individuals of cataracts. Similarly, Balog et al. ${ }^{18}$ reported that the glycation is very high in the lenses of diabetic patients and was about $40 \%$ higher than glycation in the lenses with senile cataract. Kasai et al. ${ }^{17}$ reported that the diabetic patients had increased rate of glycosylation of lens protein as compared to senile cataracts and concluded that hyperglycemia can accelerate the nonenzymatic glycation of lens protein that further induces the development of cataract in type 2 diabetes mellitus. Ansari 
et al. ${ }^{19}$ found that the extent of glycosylation was almost double in type 2 diabetic lens as compared to normal and senile cataractous lenses, which is also in agreement with our findings. Contradictory to our finding, Jansirani et al. ${ }^{8}$ reported significant increased lens glycated protein in senile cataracts compared to diabetic cataracts even though serum glucose level was higher in diabetes patients. There are various mechanisms that may explain the accelerated cataractogenesis in patients of type 2 diabetes mellitus. Of them, one major mechanism is accumulation of sorbitol in the lens. Increased levels of glucose in the lens of diabetic individuals results in an accumulation of sorbitol. This may causes osmotic swelling, eventual imbalance in the pumpleak equilibrium and finally opacification of lens. ${ }^{20,21}$ In addition, osmotic stress caused by the accumulation of sorbitol induces stress in the endoplasmic reticulum (ER), the major site of protein biosynthesis, ultimately leading to the generation of free radicals. These free radicals accelerate and aggravate cataract development. ${ }^{22}$ Glycation is considered to be another mechanism by which there occurs formation of cataract during hyperglycemia. Glycation decreases the chaperone activity of crystallin's and compromise the lens transparency. The lens protein crystalline is a long lived and is highly susceptible to post translational modifications such as glycation. Excessive non enzymatic glycation of lens proteins causes formation of advanced glycation end products (AGEs), that could further lead to opacification and hence development of cataract. ${ }^{11}$ In addition, the development of cataract in type 2 diabetes mellitus may occur as a result of three single nucleotide polymorphisms (SNPs) in chromosome 3p14.1-3p14.2. ${ }^{23}$

\section{Conclusion}

In conclusion, the development of cataract occurs as a result of glycation of lens protein crystallins. Though lens protein glycation occurs in both senile and diabetic cataract patients, the extent of glycation is greater in diabetic patients. However, further clinical studies regarding investigation of glycation of lens protein in patients of senile and diabetic cataracts are needed to accept the concept and to devise preventive measures in order to slow down the development of cataract in these individuals.

\section{Source of Funding: None.}

\section{Conflict of Interest: None.}

\section{References:}

1. Barker FM. Dietary supplementation: effects on visual performance and occurrence of AMD and cataracts. Curr Med Res Opin 2010;26(8):2011-23.

2. Lam D, Rao SK, Ratra V, Liu Y, Mitchell P, King J et al. Cataract. Nature Rev Dis Primer 2015;1:15014.

3. Song P, Wang H, Theodoratou E, Chan KY, Rudan I. The national and subnational prevalence of cataract and cataract blindness in China: a systematic review and meta-analysis. $J$ Glob Health 2018;8(1):010804.

4. Khairallah M, Kahloun R, Bourne R, Limburg H, Flaxman $\mathrm{SR}$, Jonas JB et al. Number of People Blind or Visually
Impaired by Cataract Worldwide and in World Regions, 1990 to 2010. Invest Ophthalmol Vis Sci 2015;56(11):6762-9.

5. Pascolini D, Mariotti SP. Global estimates of visual impairment: 2010. Br J Ophthalmol 2012;96:614-8.

6. Murthy GV, Gupta SK, Bachani D, Jose R, John N. Current estimates of blindness in India. Br J Ophthalmol 2005;89:25760.

7. Jain PP, Vyas A, Sogani S. Estimation of serum electrolytes $\left(\mathrm{Na}^{+}\right.$and $\left.\mathrm{K}^{+}\right)$and serum calcium levels in senile cataract patients and its comparison with non cataract patients. World $J$ Pharma Med Res. 2018;4(10):130-4.

8. Jansirani, Anathanaryanan PH. A comparative study of lens protein glycation in various forms of cataract. Indian J Clin Biochem 2004;19(1):110-2.

9. Duhaiman AS. Glycation of human lens proteins from diabetic and (nondiabetic) senile cataract patients. Glycoconj $J$ 1995;12(5):618-21.

10. Hashim Z, Zarina S. Advanced glycation end products in diabetic and non-diabetic human subjects suffering from cataract. Age (Dordr) 2011;33(3):377-84.

11. Tarwadi KV, Agte VV, Kelkar AR. Influence of selected micronutrients on glycation of human lens proteins: implications in diabetic cataract. Acta Scient Ophthalmol 20181(2):04-10.

12. Peppa M, Uribarri J, Vlassara H. Glucose, advanced glycation end products, and diabetes complications: What is new and what works. Clin Diab 2003;21:186-7.

13. Orkide D, Yorulmaz EO, Pekel H, Suyugul N. Blood and lens lipid peroxidation and antioxidant status in normal individuals, senile and diabetic cataractous patients. Cur Eye Res 2002;25(1):9-16.

14. Lowry CH, Rosebrough NJ, Farr L, Randall RJ. Protein measurement with Folin-phenol reagent. J Biol Chem 1951;193:265-75.

15. Nayak SS, Pattabiraman TN. A new colodmetric method for the es mation of glycosylated hemoglobin. Clin Chem Acta 1981;109:264-74.

16. Memon AG. Rahman A, Ahmed N. Serum glycoproteins in diabetic and non-diabetic patients with and without cataract. Pak J Ophthalmol 2008;24(3):122-7.

17. Kasai K, Nakamura T, Kase N, Hiraoka T, Suzuki R, Kogure F et al. Increased glycosylation of proteins from cataractous lenses in diabetes. Diabetologia 1983;25(1):36-8.

18. Balog Z, Klepac R, Sikić J, Jukić-Lesina T. Protein carbonylation and glycation in human lenses. Coll Antropol 2001;25:145-8.

19. Ansari NH, Awasthi YC, Srivastava SK. Role of glycosylation in protein disulfide formation and eataractogenesis. Exp Eye Res 1980;31:9-19.

20. Kinoshita JH. Mechanisms initiating cataract formation. Invest Ophthalmol 1974; 12:713-24.

21. Varma SD, Kinoshita JH. Sorbitol pathway in diabetic and galactosemic rat lens. Biochim Biophys Acta 1974;338:632640.

22. Mulhern ML, Madson CJ, Danford A, Ikesugi K, Kador $\mathrm{PF}$, Shinohara $\mathrm{T}$ et al. The unfolded protein response in lens epithelial cells from galactosemic rat lenses. Invest Ophthalmol Vis Sci 2006;47(9):3951-9.

23. Lin HJ, Huang YC, Lin JM, Wu JY, Chin LA, Lin CJ et al. Single-nucleotide polymorphisms in chromosome 3p14.13 p14.2 are associated with susceptibility of type 2 diabetes with cataract. Molecular Vision 2010;16:1206-14.

How to cite this article: Shukla $\mathrm{P}$, Arora M, Mahat RK, Kumar S, Sah SP. Lens protein glycation in diabetic and senile cataract patients. Indian J Clin Exp Ophthalmol. 2019;5(3):395-7. 